\title{
Structural Abnormalities and Deficient Maintenance of Peripheral Nerve Myelin in Mice Lacking the Gap Junction Protein Connexin 32
}

\author{
Patrizia Anzini, ${ }^{1}$ Dirk H.-H. Neuberg, ${ }^{2}$ Melitta Schachner, ${ }^{1,3}$ Eric Nelles, ${ }^{4}$ Klaus Willecke, ${ }^{4}$ Jürgen Zielasek, ${ }^{5}$ \\ Klaus V. Toyka, ${ }^{5}$ Ueli Suter, ${ }^{2}$ and Rudolf Martini ${ }^{1,5}$ \\ Departments of ${ }^{1}$ Neurobiology and ${ }^{2} \mathrm{Cell}$ Biology, Swiss Federal Institute of Technology, $\mathrm{CH}-8093$ Zurich, Switzerland, \\ 3/nstitute of Biosynthesis of Neural Structures, Center for Molecular Neurobiology Hamburg, University of Hamburg, D- \\ 20246 Hamburg, Germany, ${ }^{4}$ Institute of Genetics, University of Bonn, D-53117 Bonn, Germany, and 5 Department of \\ Neurology, University of Würzburg, D-97080 Würzburg, Germany
}

\begin{abstract}
Mutations affecting the connexin 32 (Cx32) gene are associated with the X-linked form of the hereditary peripheral neuropathy Charcot-Marie-Tooth disease (CMTX). We show that Cx32deficient mice develop a late-onset progressive peripheral neuropathy with abnormalities comparable to those associated with CMTX, thus providing proof of the critical role of $\mathrm{C} \times 32$ in the maintenance of peripheral nerve myelin and an animal model for CMTX. Frequently observed features include abnormally thin myelin sheaths, cellular onion bulb formation reflect-
\end{abstract}

ing myelin degeneration-induced Schwann cell proliferation, and enlarged periaxonal collars while nerve conductance properties are altered only slightly. These observations are consistent with earlier hypotheses suggesting a function of $\mathrm{C} \times 32$ as a channel-forming protein that facilitates the communication between the abaxonal and adaxonal aspects of Schwann cell cytoplasm.

Key words: connexin 32; myelin; Schwann cell; demyelination; Charcot-Marie-Tooth disease; transgenic mouse
Connexins are members of a large gene family encoding subunit proteins of gap junctions (for review, see Bruzzone et al., 1996; Kumar and Gilula, 1996; Bruzzone and Ressot, 1997). These structures consist of oligomerized connexin proteins that form intercellular channels to allow the exchange of small molecules ( $<1000 \mathrm{Da})$ like ions, second messengers, and metabolites. This communication among neighboring cells is thought to be important for the propagation of signals among electrically excitable cells and for the regulation of cell proliferation and differentiation during tissue development and in carcinogenesis.

Defective connexin genes have been suggested to cause two human genetic diseases. First, single nucleotide mutations in the connexin 43 (Cx43) gene have been described to occur frequently in patients exhibiting familial cardiac malformation (Britz-Cunningham et al., 1995), and genetically engineered mice with deleted Cx43 gene show heart malformations as well (Reaume et al., 1995). Second, mutations in the human Cx32 gene have been linked to the X-linked hereditary motor and sensory neuropathy Charcot-Marie-Tooth disease (CMTX; Bergoffen et al., 1993) (for review, see Ionasescu et al., 1996), which is characterized by distal muscle weakness, muscle atrophy, areflexia, and foot deformities (for review, see Suter and Snipes, 1995). In concord with the demyelinating phenotype of CMTX patients, Cx32 is highly expressed by myelinating Schwann cells in the PNS and is regulated comparably to other myelin proteins (Scherer et al., 1995). Two of these proteins, protein zero (P0)

Received Jan. 27, 1997; revised March 19, 1997; accepted March 31, 1997.

P.A. was supported by the Associazione per la Promozione delle Ricerche Neurologiche (Italy). The laboratory of K.W. was supported by the Deutsche Forschungsgemeinschaft (SFB 284, C1) and the Dr. Mildred Scheel Foundation for Cancer Research. The laboratory of U.S. was supported by the Swiss National Science Foundation.

Correspondence should be addressed to Dr. Rudolf Martini, Department of Neurology, Section of Developmental Neurobiology, University of Würzburg, Josef Schneider Strasse 11, D-97080 Würzburg, Germany.

Copyright (C) 1997 Society for Neuroscience $0270-6474 / 97 / 174545-07 \$ 05.00 / 0$ and peripheral myelin protein 22 (PMP22), are affected in alternative forms of CMT, exhibiting demyelinating phenotypes as well (for review, see Snipes and Suter, 1995; Suter and Snipes, 1995; Murakami et al., 1996). However, in contrast to P0 and PMP22, which are components of compact myelin, Cx32 is found mainly in noncompacted domains, the paranodal loops, and Schmidt-Lanterman incisures (Bergoffen et al., 1993; Scherer et al., 1995; Spray and Dermietzel, 1995). On the basis of this localization, it has been hypothesized that $\mathrm{Cx} 32$ may be a component of reflexive intracellular gap junctions established between different, noncompacted myelin membrane leaflets to provide a direct diffusion pathway transversing the myelin sheath (Paul, 1995; Scherer et al., 1995). Because some CX32 mutations of CMTX patients interrupt the formation of functional gap junctions in vitro (Bruzzone et al., 1994; Rabadan-Diehl et al., 1994; Omori et al., 1996), they probably lead to a blockade of the direct diffusion pathway within the myelin sheath, leading to pathological alterations in the peripheral nerve.

In this report we show that $\mathrm{Cx} 32$-deficient mice display a late-onset peripheral neuropathy with features similar to those of CMTX patients, hence strongly supporting the causative role of $\mathrm{Cx} 32$ mutations in CMTX. The demyelinating phenotype of the neuropathy is accompanied by mild changes of the conduction properties of peripheral nerves. Additionally observed abnormalities, i.e., enlarged periaxonal collars and noncompacted regions of myelin, are consistent with a role of $\mathrm{Cx} 32$ in transport processes, in particular ionic homeostasis, in and across myelin sheaths.

\section{MATERIALS AND METHODS}

Genotyping. The presence of wild-type or mutant Cx32 alleles was detected simultaneously by using a set of three specific primers in the PCR. The wild-type Cx32 allele was represented as a 881 bp fragment, using two primers that were complementary to sequences in the $\mathrm{Cx} 32$ gene initially published by Hennemann et al. (1992) (oligonucleotide sequences: 5'-CCATAAGTCAGGTGTAAAGGAGC-3' and 5'-GAGCATAA- 
A

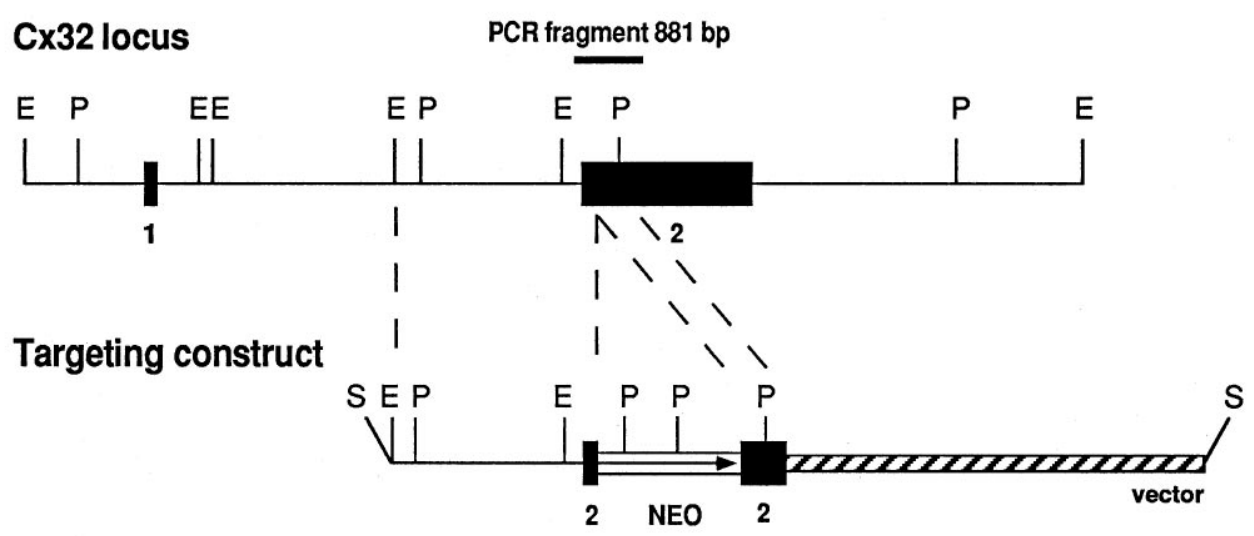

Targeted allele

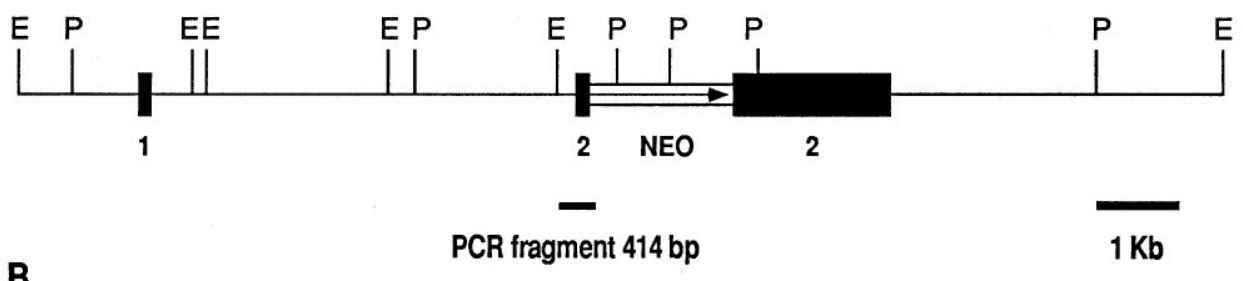

Figure 1. Genotyping of Cx32 mutant mice. $A$, Partial restriction map of the $\mathrm{Cx} 32$ locus and schematic representation of the targeting construct and the targeting event. Homologous recombination resulted in an "in frame" insertion of the promoterless neo cassette and the concomitant disruption of the translated exon (exon 2). Exons are indicated as filled boxes. The neo cassette (NEO) is represented by an open box. $E$, EcoRI; P, PstI; S, SacII. Amplified PCR fragments are indicated with a thick line. $B$, PCR analysis of the Cx32 locus and the targeting event in transgenic animals (control, no DNA added).
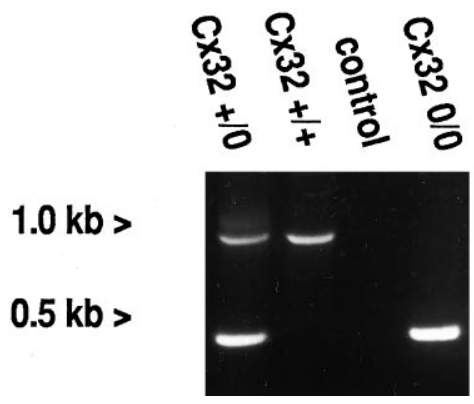

AGACAGTGAAGACGG-3'). Additional use of an oligonucleotide primer complementary to the neo resistance cassette sequences amplified a $414 \mathrm{bp}$ fragment specific for the disrupted allele (5'-ATCATGCGAAACGATCCTCATCC-3'). The PCR was performed in a final volume of $25 \mu \mathrm{l}$ $\left(2.5 \mathrm{mM} \mathrm{MgCl}_{2}, 1 \times\right.$ PCR buffer, $0.4 \mathrm{mM}$ dGTP, dATP, dCTP, dTTP, $4 \mu \mathrm{M}$ of each of the three primers, $1 \mathrm{U}$ Taq DNA polymerase, and 1-3 $\mu \mathrm{g}$ genomic DNA). The reaction product was denatured at $93^{\circ} \mathrm{C}$ for $2 \mathrm{~min}$, followed by 40 cycles $\left(93^{\circ} \mathrm{C}, 30 \mathrm{sec} ; 66^{\circ} \mathrm{C}, 45 \mathrm{sec} ; 72^{\circ} \mathrm{C}, 90 \mathrm{sec}\right)$ and a final extension at $72^{\circ} \mathrm{C}$ for 10 min with an MWG Biotech thermal cycler.

Tissue preservation for electron microscopy. Electron microscopy of femoral nerves (comprising the quadriceps muscle and saphenous nerve branches) of transcardially perfused Cx32-deficient and wild-type mice (2\% paraformaldehyde and $2 \%$ glutaraldehyde in $0.1 \mathrm{~m}$ cacodylate buffer) was performed as described (Martini et al., 1995a,b).

Morphometry. Onion bulbs, unusually thin myelin, and other abnormalities (e.g., abnormally enlarged periaxonal collars) were quantified at the electron microscopic level by scoring their numbers in cross sections of femoral quadriceps and saphenous nerves (Carenini et al., 1997). For each developmental stage two to four wild-type and three Cx32-deficient mice were investigated (see Fig. 2). No detectable differences in the morphological abnormalities between homozygous female and hemizygous male mice were observed. Significance of differences between mean values of each developmental stage investigated was determined by a one-way ANOVA, followed by Spjotvoll-Stoline post hoc tests using a commercially available statistical software (Superanova). The Spjotvoll-Stoline test was only performed when the one-way ANOVA indicated overall statistical significance $(p<0.01)$.

Electrophysiological measurements. The determination of nerve conduc- tion properties was performed in six hemizygous $\mathrm{Cx} 32$-deficient male mice (142-181 d old), seven age-matched wild-type mice (123-150 d old), seven homozygous Cx32-deficient female mice (351-387 d old), and four female and six male wild-type mice (358-396 d old). Determination of latencies, amplitudes, and duration of the compound muscle action potentials (M-latencies, M-amplitudes, CMAP) and the determination of the elicitability, latency, and duration of the F-waves (which are late motor responses sensitive to myelin dysfunction) and of mixed afferent sciatic nerve potential latencies was performed as described in detail (Zielasek et al., 1996). Statistical analysis was performed by using the one-sided $U$ test at a significance level of 0.05 to assess the statistical significance of differences in the nerve conduction studies between $\mathrm{Cx} 32$ deficient mice and control mice (Instat, GraphPad, San Diego, CA).

\section{RESULTS}

\section{Genotyping of Cx32-deficient animals}

The construction of Cx32-deficient mice has been described (Nelles et al., 1996). To establish a fast method for genotyping and the identification of mutant animals, we devised a PCR-based strategy (Fig. 1A). Using in the same PCR simultaneously three oligonucleotide primers specific for (1) the neo expression cassette, (2) sequences $5^{\prime}$ upstream of the neo cassette insertion into exon 2 of the Cx32 gene, and (3) sequences $3^{\prime}$ downstream of the insertion, we 


\begin{tabular}{|c|c|c|c|c|}
\hline Genotype & Cx32-deficient & wild type & Cx32-deficient & Wild type \\
\hline$n$ & 6 & 7 & 7 & 10 \\
\hline Age & 4-6 months & 4-6 months & 1 year & 1 year \\
\hline \multicolumn{5}{|l|}{ Facial nerve } \\
\hline M-latency (msec) & $1.0 \pm 0.1$ & $1.1 \pm 0.1$ & $1.0 \pm 0.1$ & $1.1 \pm 0.2$ \\
\hline M-amplitude (mV) & $15 \pm 2$ & $12 \pm 4$ & $11 \pm 2^{*}$ & $14 \pm 3$ \\
\hline \multicolumn{5}{|l|}{ Sciatic nerve } \\
\hline \multicolumn{5}{|l|}{ Proximal stimulation } \\
\hline M-latency (msec) & $1.7 \pm 0.2^{\mathrm{ns}}$ & $1.5 \pm 0.2$ & $1.5 \pm 0.2$ & $1.6 \pm 0.2$ \\
\hline M-amplitude (mV) & $8 \pm 3^{*}$ & $12 \pm 3$ & $10 \pm 6$ & $11 \pm 4$ \\
\hline M-duration (msec) & $2.2 \pm 0.2^{\mathrm{ns}}$ & $1.8 \pm 0.5$ & $2.0 \pm 0.5^{\mathrm{ns}}$ & $2.2 \pm 0.5$ \\
\hline F-latency (msec) & $4.2 \pm 0.2$ & $4.1 \pm 0.2$ & $4.4 \pm 0.4$ & $4.4 \pm 0.5$ \\
\hline \multicolumn{5}{|l|}{ Distal stimulation } \\
\hline M-latency (msec) & $1.0 \pm 0.1^{*}$ & $0.8 \pm 0.1$ & $0.8 \pm 0.1$ & $1.0 \pm 0.2$ \\
\hline M-amplitude (mV) & $11 \pm 4^{\mathrm{ns}}$ & $15 \pm 5$ & $12 \pm 3$ & $12 \pm 4$ \\
\hline M-duration (msec) & $2.1 \pm 0.2$ & $1.5 \pm 0.3$ & $1.9 \pm 0.6^{\mathrm{ns}}$ & $2.2 \pm 0.5$ \\
\hline F-latency (msec) & $4.8 \pm 0.5$ & $4.8 \pm 0.2$ & $5.1 \pm 0.4^{\mathrm{ns}}$ & $4.8 \pm 0.5$ \\
\hline Motor nerve conduction velocity $(\mathrm{m} / \mathrm{sec})$ & $32 \pm 9$ & $35 \pm 9$ & $35 \pm 10^{\mathrm{ns}}$ & $40 \pm 12$ \\
\hline Mixed afferent nerve conduction velocity $(\mathrm{m} / \mathrm{sec})$ & $42 \pm 6$ & $45 \pm 3$ & $49 \pm 8$ & $49 \pm 9$ \\
\hline
\end{tabular}

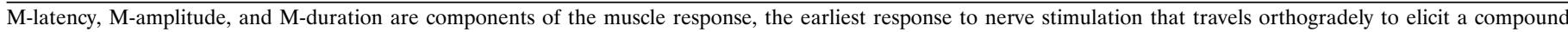

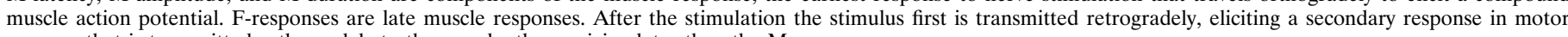
neurons that is transmitted orthogradely to the muscle, thus arriving later than the M-response.

${ }^{*} p<0.05$, one-sided $U$ test; ${ }^{\text {ns }}$, not significant.

were able to genotype the animals conveniently and reliably (Fig. $1 B)$.

\section{Behavior of $\mathbf{C x 3 2 - d e f i c i e n t ~ a n i m a l s}$}

Cx32-deficient animals were viable, bred normally, and had usual life spans. No obvious behavioral abnormalities could be observed up to 15 months of age (data not shown). In particular, no signs of peripheral neuropathies were detectable, if these animals were compared with mice with severe myelin abnormalities (Giese et al., 1992; Suter et al., 1992a,b; Adlkofer et al., 1995; Martini et al., 1995a,b; Magyar et al., 1996).

\section{Conduction properties of peripheral nerves}

The electrophysiological evaluation revealed only mild abnormalities (Table 1). In 4- to 6-month-old mutants the only detectable changes were a slight conduction slowing and an increase of the latency of the muscle response (M-latency) after distal stimulation of the sciatic nerve. Another statistically significant change in mutant mice was a reduction of the $\mathrm{M}$-amplitude after proximal sciatic nerve stimulation. These changes indicate a mild mixed axonal and demyelinating pathology as represented by a reduction of M-amplitudes and delayed muscle responses, respectively.

Unexpectedly, in 1-year-old mice the abnormalities were even milder than in the 4- to 6-month-old mutants, with a decrease of M-amplitudes only in the facial nerve and a tendency toward a mild conduction slowing in the sciatic nerve (Table 1).

\section{Ultrastructure of peripheral nerves}

We chose to investigate the quadriceps muscle and the cutaneous saphenous branches of the femoral nerve to distinguish the effects of Cx32 deficiency on motor and sensory nerves. Axon-Schwann cell units of 4-week-old Cx32-deficient mice were morphologically not distinguishable from those of wild-type littermates (Fig. 2). However, in the quadriceps nerves of 4-month-old mutants, $\sim 25 \%$ of myelin- ated axon-Schwann cell units were associated with small Schwann cells and Schwann cell processes not in contact with axons and surrounded by a basal lamina (Figs. $2 a, 3 a-d$ ). Such structures are indicative of myelin degeneration-induced Schwann cell proliferation in peripheral neuropathies and are, because of their concentric arrangement around the myelinating axon-Schwann cell units, called onion bulbs (Dyck et al., 1993). The corresponding myelinating axon-Schwann cell units in the center of the onion bulbs were usually thinly myelinated in comparison to the axon caliber (Fig. $3 a-d$ ), suggesting remyelination after myelin degeneration (Dyck et al., 1993). In quadriceps nerves of 6-month-old and 1-year-old Cx32deficient mice, onion bulbs and thinly myelinated axons were more frequent than in 4-month-old mutants, reflecting a progressive course of myelin degeneration (Fig. $2 a$ ). Occasionally in 1-year-old mice, onion bulb cells collectively surrounded two or more axonSchwann cell units as a group (Fig. $3 c$ ). Such profiles were not seen in other myelin mutants such as P0- and PMP22-deficient mice and are reminiscent of "regenerating units" usually found in proximal stumps of transected nerves (Morris et al., 1972). Interestingly, onion bulbs and thinly myelinated axon-Schwann cell units were seen only very rarely in the saphenous nerves of 4- and 6-month-old and 1-year-old mutants, and their numbers were not significantly different from those seen in the corresponding nerves of wild-type mice (Fig. 2a).

In addition to onion bulbs and thinly myelinated axons, other abnormalities were seen in the Cx32-deficient mice. Particularly striking was the occurrence of axon-myelin units with abnormally thick periaxonal collars (Fig. $3 d, g$ ). Either they were of high electron density (Fig. 3g), or they contained many vesicular inclusions (Fig. $3 d$ ). In addition, they often showed intimate interdigitations with the axon reminiscent of the paranodal axon-Schwann cell network (for literature, see Gatzinsky, 1996) (Fig. 3e,f). At 4 months of age, the 


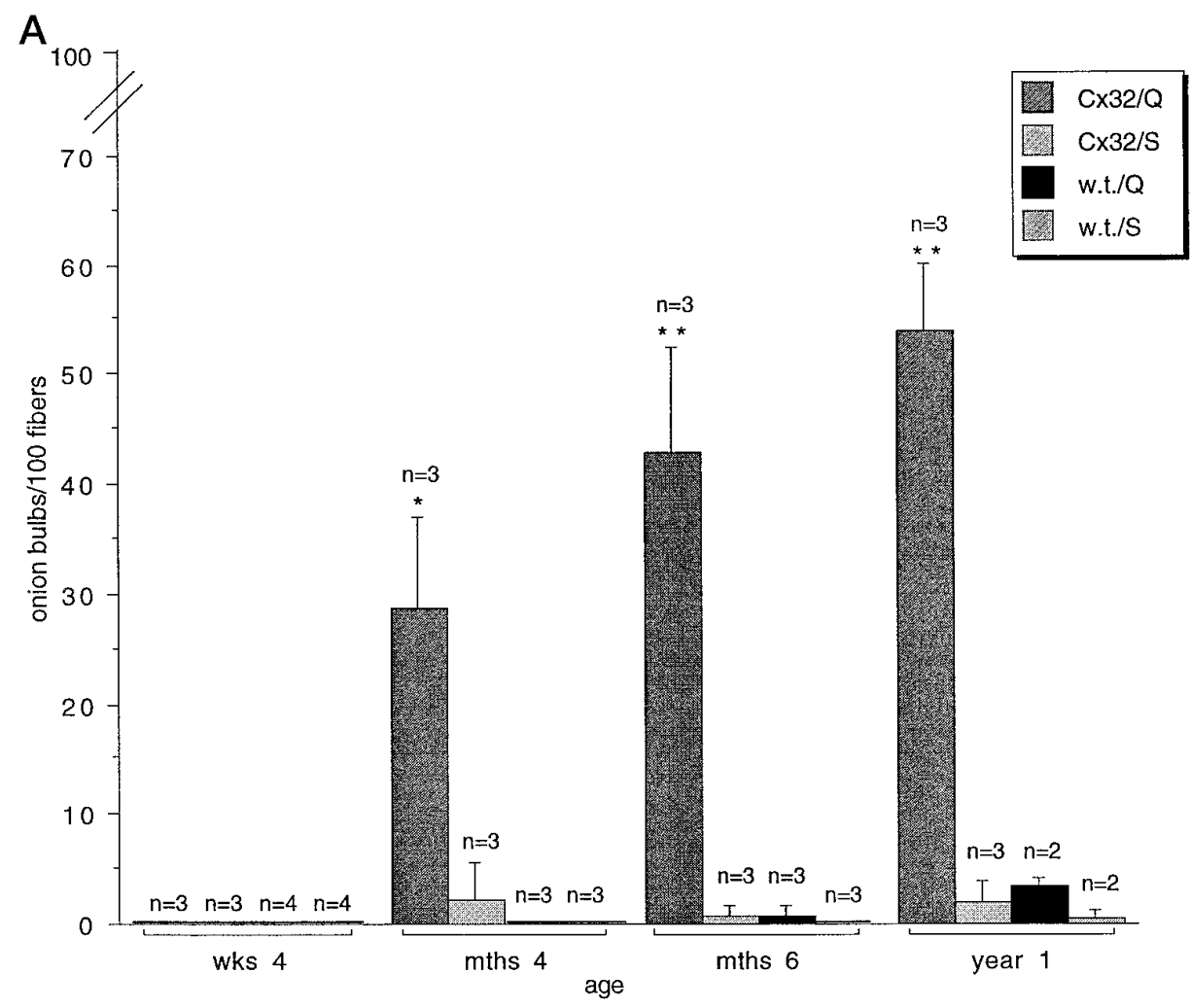

B

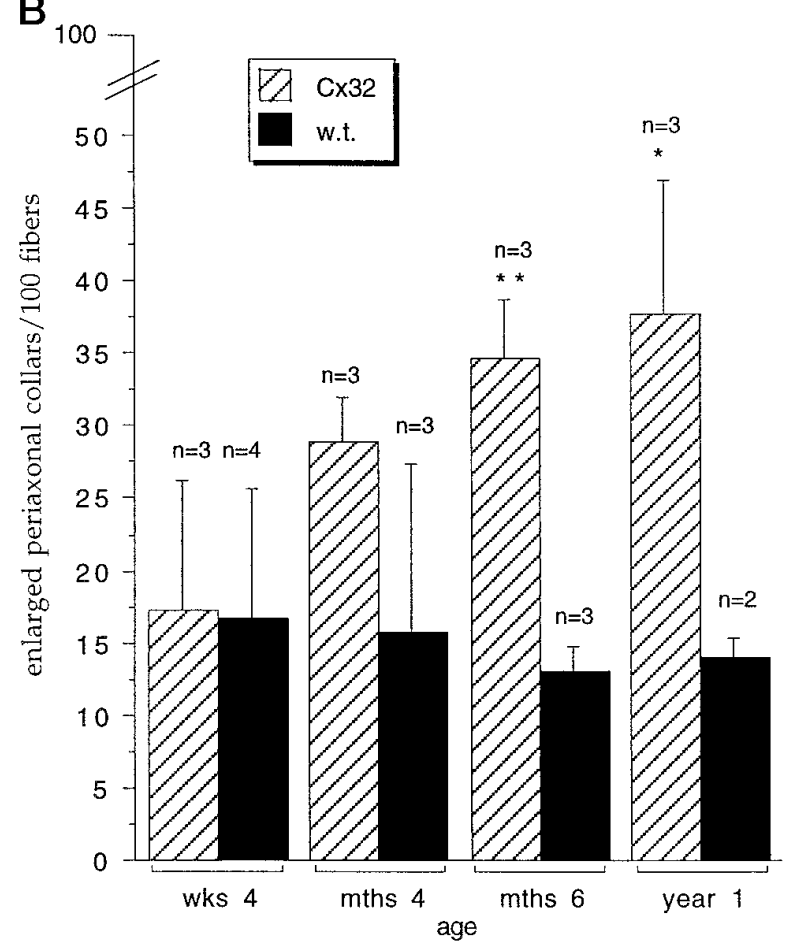

$\mathrm{C}_{100}$

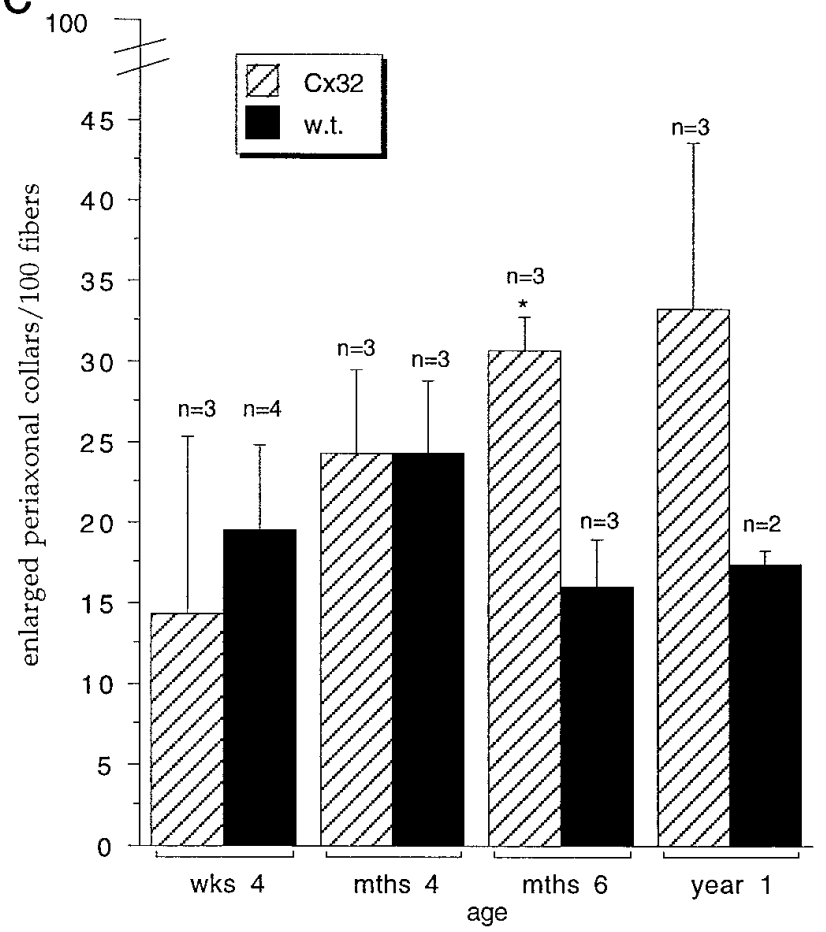

Figure 2. Schematic representation of the number of onion bulbs $(A)$ and abnormally enlarged periaxonal collars $(B, C)$ in femoral nerves of Cx32-deficient and wild-type mice at 4 weeks, 4 and 6 months, and 1 year of age. $a$, Note that onion bulbs develop only in the quadriceps nerve of Cx32-deficient mice $(C x 32 / Q)$ older than 4 months, whereas such structures are absent or found only very rarely in the saphenous nerve of the mutant $(C x 32 / S)$ and in the quadriceps (w.t./Q) and saphenous nerves (w.t./S) of the wild-type mice. *Significantly different compared with wild-type mice ( $p<$ $0.05)$; ** significantly different compared with wild-type mice $(p<0.01) . n$ indicates the number of mice investigated. $B, C$, At 6 months of age, both in quadriceps $(B)$ and saphenous nerves $(C)$, the number of abnormally enlarged periaxonal collars is elevated significantly in Cx32-deficient mice when compared with values from wild-type mice. The lack of significance in saphenous nerves of 1-year-old mice possibly can be explained by the large SDs. *Significantly different compared with wild-type mice $(p<0.05)$; **significantly different compared with wild-type mice $(p<0.01)$. $n$ indicates the number of mice investigated. 

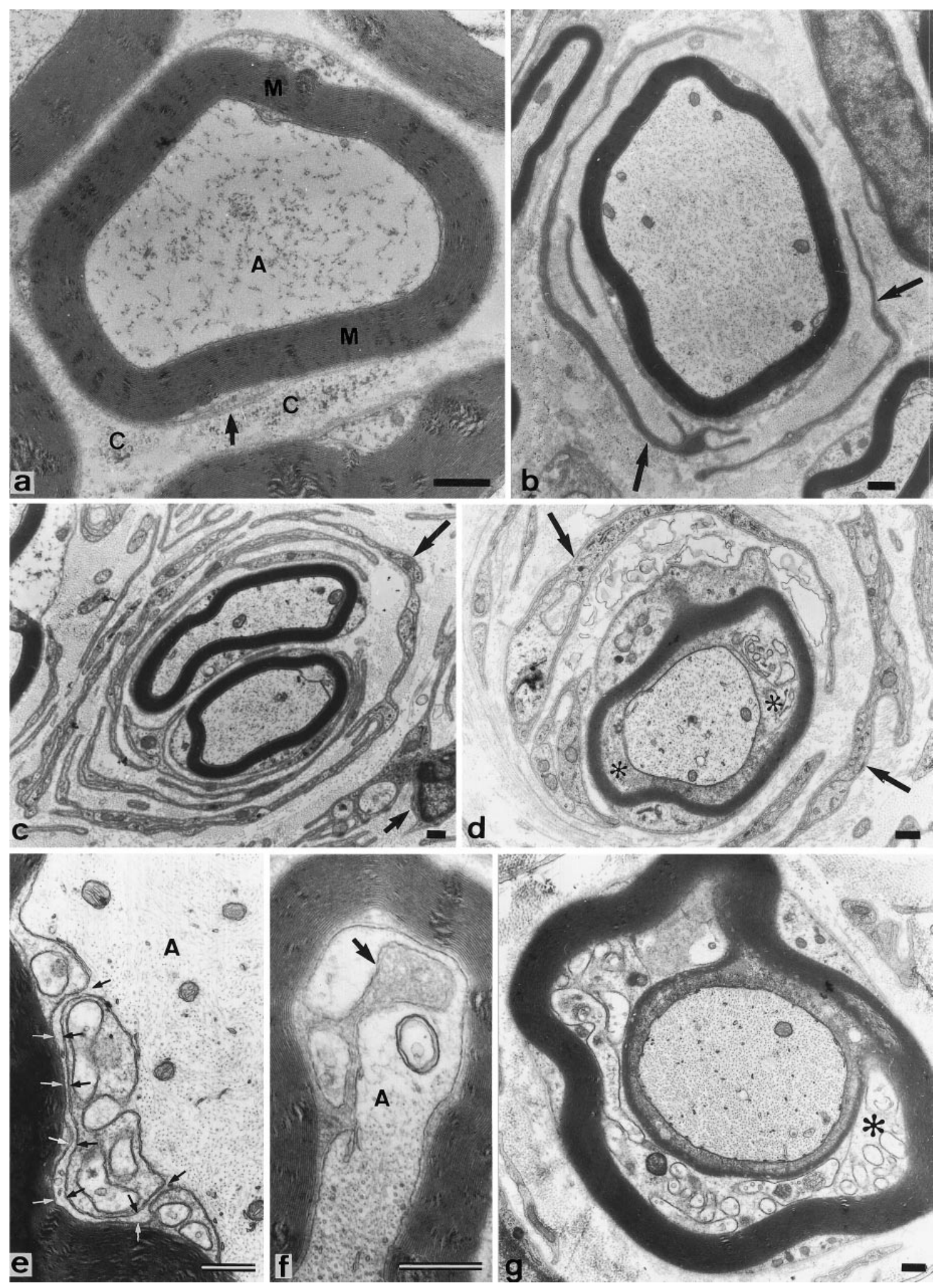

Figure 3. Electron migrographs of axon-Schwann cell units of wild-type $(a)$ and connexin 32-deficient mice $(b-g)$ at $4(a, b)$ and $6(e-g)$ months and 1 year of age $(c, d) . a$, This axon $(A)$ is enveloped by a sheath of compacted myelin $(M)$. A basal lamina around the myelinating Schwann cell (arrow) and endoneurial collagen $(C)$ separates the axon-Schwann cell unit from neighboring nerve fibers. $b$, This myelinated axon-Schwann cell unit is characterized by thin, compacted myelin surrounded by basal lamina-covered processes of Schwann cells forming an onion bulb (arrows). $c$, This onion bulb contains two myelinated axon-Schwann units. Large and small arrows point to a process and cell body of onion bulb cells, respectively. $d$, Axon-Schwann cell unit surrounded by processes of onion bulb cells (arrows). Note the expanded periaxonal collar containing vesicular inclusions (asterisks). $e, f$, Intimate interdigitations between the inner aspect of the Schwann cell and the axon $(A)$. In $e$, the small arrows delineate a slender, loop-shaped protrusion of the axon $(A)$ engulfing Schwann cell and/or axonal cytoplasm. In $f$, a cytoplasmic extension of the Schwann cell collar (arrow) protrudes into the axon. $g$, Abnormally organized noncompacted aspect of a myelinating Schwann cell (asterisk). Note the numerous vesicular inclusions and the expanded periaxonal collar of high electron density. Scale bars, $0.5 \mu \mathrm{m}$. 
numbers of enlarged periaxonal collars were slightly, but not significantly, elevated in the quadriceps nerve of the mutants (Fig. 2b), whereas in the saphenous nerve the numbers of enlarged periaxonal collars were not elevated (Fig. 2c). In 6-month-old mice the numbers of enlarged periaxonal collars were elevated significantly in the mutants in comparison with wild-type mice in both the quadriceps nerve and the saphenous nerve (Fig. $2 b, c$ ). At 1 year of age, the numbers of enlarged periaxonal collars still were elevated significantly in quadriceps nerves (Fig. $2 b$ ), whereas the higher numbers in the saphenous nerves of the mutants were no longer statistically significant (Fig. 2c), possibly because of the relatively high SDs.

Morphological alterations, less frequently observed than enlarged periaxonal collars, were abnormally organized noncompacted aspects of myelinating Schwann cells. They usually consisted of blown-up cytoplasm containing lysosomes, multivesicular bodies, and other vesicular structures and were characterized by numerous infoldings (Fig. $3 g$ ).

In contrast to myelinating axon-Schwann cell units, nonmyelinating axon-Schwann cell units showed no abnormalities in the mutants at any age investigated (data not shown).

\section{DISCUSSION}

In the present study we demonstrate that Cx32-deficient mice develop a late-onset and progressive peripheral neuropathy with features indicative of demyelination and remyelination, such as onion bulbs and abnormally thin myelin. Noncompacted aspects of myelin, such as periaxonal collars, were unusually enlarged. The abnormalities in conduction properties were only mild, in keeping with a normally appearing phenotype and lack of detectable muscle weakness.

In the past, strains of mice deficient in the myelin proteins $\mathrm{P} 0$, PMP22, and MAG have been generated. Mice homozygously mutated in $\mathrm{P} 0$ are characterized by severely compromised myelination and progressive demyelination (Giese et al., 1992; Martini et al., 1995b). Similarly, homozygous PMP22-deficient mutants show abundant focal hypermyelination in the form of myelin tomacula at a young age, followed by severe demyelination (Adlkofer et al., 1995). These findings are in contrast to the phenotype of the Cx32-deficient mice, which show normal myelin formation and nerve conduction at younger ages (Nelles et al., 1996; this study), followed by a mild demyelinating and remyelinating phenotype (this study). Similar progress in demyelination has been described in mice heterozygously deficient in $\mathrm{P} 0\left(\mathrm{P}^{+/-}\right.$mice $)$or homozygously deficient in MAG $\left(\mathrm{MAG}^{-/-}\right.$mice). In $\mathrm{P}^{+/-}$mice normal myelin formation is found until postnatal week 10 , followed by abnormal myelin folding in the paranodal aspects of the myelin and onion bulb formation at postnatal week 16 (Martini et al., 1995b). In $\mathrm{MAG}^{-/-}$mutants the first abnormalities occur at postnatal week 12, when both myelin tomacula and features characteristic of degeneration of myelin and axons are detectable (Fruttiger et al., 1995; Carenini et al., 1997). Thus, these mutants form normal myelin from the outset, followed by genotype-specific alterations (e.g., paranodal foldings, tomacula formation) that probably lead to, or are concomitant with, demyelination. Consequently, the formation of myelin appears to be considerably less sensitive to molecular alterations of myelin genes than the maintenance of myelin.

\section{Possible mechanisms leading to peripheral neuropathies in Cx32-deficient mice}

A genotype-specific characteristic feature in the Cx32-deficient mice is the elaboration of abnormally thick periaxonal collars and cytoplasmic thickenings of other noncompacted compartments, such as Schmidt-Lanterman incisures and paranodal loops. How can the occurrence of cytoplasmic swellings be linked to the absence of a gap junction protein? In wild-type mice Cx32 is expressed at apposing membranes of Schmidt-Lanterman incisures that potentially could be used as rapid pathways for ions and small molecules to move between the cell body and inner myelin compartments. Thus, the disorganization of the inner Schwann cell compartment in Cx32-deficient mice might reflect poor communication between the outer and inner cytoplasmic aspects of myelinating Schwann cells that eventually leads to cytoplasmic abnormalities (see also the discussion by Scherer et al., 1995). Alternatively, or in addition, the cytoplasmic swelling may represent pathological alterations caused by a compromised homeostasis of ions as a result of reduced "spatial buffering" of ions after neuronal activity (Spray and Dermietzel, 1995).

The observed abnormalities might represent a pathological state of a Schwann cell that is prone to demyelination. However, not all Schwann cells with cytoplasmic thickenings undergo demyelination, because in the saphenous nerve branch no signs of demyelinations could be found, although cytoplasmic thickenings were present. The much lower liability to myelin degeneration in the cutaneous sensory nerves and dorsal roots versus muscle nerves and ventral roots also has been described for $\mathrm{P}^{+/-}$, $\mathrm{PMP}_{2} 2^{+/-}, \mathrm{MAG}^{-/-}$mice and in rats overexpressing PMP22 (Adlkofer et al., 1995; Fruttiger et al., 1995; Martini et al., 1995b; Sereda et al., 1996; Carenini et al., 1997). However, the underlying cellular and molecular differences between sensory and motor fibers have not yet been determined.

\section{Cx32-deficient mice show abnormalities similar to those in CMTX patients}

Unlike P0, MAG, and PMP22, Cx32 originally had not been described as a typical myelin component, because it had been detected in liver, kidney, pancreas, and brain (Spray and Dermietzel, 1995). Cx32 emerged into prominence as a myelin protein when mutations in this X-linked gene were found to be linked to the dominantly inherited form of CMTX (Bergoffen et al., 1993), the most common nonduplication form of CMT1 (Ionasescu et al., 1996). Meanwhile, more than 80 mutations are known to be associated with CMTX (Scherer et al., 1997). The various mutations are dispersed throughout the coding region of the Cx32 gene and lead to amino acid substitutions, codon deletions, frameshift, and nonsense mutations (Sherer et al., 1997). The products of three Cx32 mutations (two different amino acid substitutions and a frameshift mutation) cause a loss of function in that the gene products are unable to form functional channels (Bruzzone et al., 1994). Additionally, these mutations lead to the inability to form channels with $\mathrm{Cx} 26$, indicating also a dominant-negative effect on $\mathrm{Cx} 26$ proteins that might associate with mutant Cx32 molecules (Bruzzone et al., 1994). However, because Cx26 is not or only very scarcely expressed by myelinating Schwann cells (Scherer et al., 1995), faulty interactions of mutant $\mathrm{C} \times 32$ with $\mathrm{Cx} 26$ are probably not relevant for the severity of CMTX. Together with investigations on the functional consequences of $\mathrm{Cx} 32$ mutations in vivo, the search for other possible partners of Cx32 in peripheral nerves might be relevant to understand the significant variability in the clinical profile of CMTX patients (Ionasescu et al., 1996; Timmerman et al., 1996; Yoshimura et al., 1996; Scherer et al., 1997).

Mice deficient in Cx32 are affected by a mild phenotype in that myelination occurs normally and on schedule. The late onset of the neuropathy is reminiscent of the situation in CMTX patients who reveal clinical symptoms in the second or third decade of life (Ionasescu et al, 1996). However, because the behavior of the 
mutant mice is not distinguishable from that of wild-type mice, one could argue that the mice do not mirror exactly the phenotype of CMTX patients. It should, however, be considered that small organisms with relatively short nerves might be less susceptible to impaired conductance properties than humans are.

A typical electrophysiological feature of Cx32-deficient mice is the mild, but significant, axonal component of the abnormality as reflected by a decrease in the M-amplitude. Similar electrophysiological alterations are one of the hallmark symptoms of patients suffering from CMTX, causing some difficulties in distinguishing them from patients with CMT2, the axonal form of CMT (Timmerman et al., 1996) (for review, see Dyck et al., 1993). Our electron microscopic analysis provided no evidence for a massive loss of axons in Cx32-deficient mice, in contrast to the results of the electrophysiological investigations. However, it is possible that the lowering of the M-response is the physiological consequence of axon-related alterations, such as periaxonal swellings and axon-Schwann cell interdigitations, rather than of demyelination. In addition, a mild and transient axonal damage cannot be ruled out and might contribute to the axon-related electrophysiological changes. It is not clear why the decrease in amplitude was visible only at younger age. It is, however, conceivable that the regenerating units that have been seen occasionally in the nerves of 1-year-old, but not of 4- to 6-month-old, mutant mice cause or contribute to the amelioration of the electrophysiological properties. Further studies are needed to learn whether and how the nervous system can compensate for the impaired myelin maintenance in some inherited neuropathies.

\section{REFERENCES}

Adlkofer K, Martini R, Aguzzi A, Zielasek J, Toyka KV, Suter U (1995) Hypermyelination and demyelinating peripheral neuropathy in PMP22deficient mice. Nat Genet 11:274-280.

Bergoffen H, Scherer SS, Wang S, Oronzi-Scott S, Bone L, Paul DL, Chen K, Lensch MW, Chance PF, Fischbeck KH (1993) Connexin mutations in X-linked Charcot-Marie-Tooth disease. Science 262:2039-2042.

Britz-Cunningham SH, Shah MM, Zuppan CW, Fletcher W (1995) Mutations of the Connexin 43 gap-junction gene in patients with heart malformations and defects of laterality. N Engl J Med 332:1323-1329.

Bruzzone R, Ressot C (1997) Connexins, gap junctions, and cell-cell signalling in the nervous system. Eur J Neurosci 9:1-6.

Bruzzone R, White TW, Scherer SS, Fischbeck KH, Paul DL (1994) Null mutations of connexin 32 in patients with X-linked Charcot-MarieTooth disease. Neuron 13:1253-1260.

Bruzzone R, White TW, Paul DL (1996) Connections with connexins: the molecular basis of direct intercellular signaling. Eur J Biochem 238:1-27.

Carenini S, Montag D, Cremer H, Schachner M, Martini R (1997) Absence of the myelin-associated glycoprotein (MAG) and the neural cell adhesion molecule (N-CAM) interferes with the maintenance but not with the formation of peripheral myelin. Cell Tissue Res 287:3-9.

Dyck PJ, Chance P, Lebo R, Carney JA (1993) Hereditary motor and sensory neuropathies. In: Peripheral neuropathy (Dyck PJ, Thomas PK, Griffin JW, Low PA, Poduslo JF, eds), pp 1094-1136. Philadelphia: Saunders.

Fruttiger M, Montag D, Schachner M, Martini R (1995) Crucial role of the myelin-associated glycoprotein in the maintenance of axon-myelin integrity. Eur J Neurosci 7:511-515.

Gatzinsky KP (1996) Node-paranode regions as local degradative centres in alpha-motor axons. Microsc Res Tech 34:492-506.

Giese KP, Martini R, Lemke G, Soriano P, Schachner M (1992) Mouse P0 gene disruption leads to hypomyelination abnormal expression of recognition molecules and degeneration of myelin and axons. Cell 71:565-576.

Hennemann H, Kozjek G, Dahl E, Nicholson B, Willecke K (1992) Molecular cloning of mouse connexins 26 and 32: similar genomic organization but distinct promoter sequences of two gap junction genes. Eur J Cell Biol 58:81-89.

Ionasescu V, Ionasescu R, Searby C (1996) Correlation between connexin 32 gene mutations and clinical phenotype in X-linked dominant Charcot-Marie-Tooth neuropathy. Am J Med Genet 63:486-491.
Kumar NM, Gilula NB (1996) The gap junction communication channel. Cell 84:381-388.

Magyar JP, Martini R, Ruelicke T, Aguzzi A, Adlkofer K, Dembic Z, Zielasek J, Toyka KV, Suter U (1996) Impaired differentiation of Schwann cells in transgenic mice with increased PMP22 gene dosage. J Neurosci 16:5351-5360.

Martini R, Mohajeri MH, Kasper S, Giese KP, Schachner M (1995a) Mice doubly deficient in the genes for $\mathrm{P} 0$ and myelin basic protein show that both proteins contribute to the formation of the major dense line in peripheral nerve myelin. J Neurosci 15:4488-4495.

Martini R, Zielasek J, Toyka KV, Giese KP, Schachner M (1995b) $\mathrm{P}_{0^{-}}$ deficient mice show myelin degeneration in peripheral nerves characteristic of inherited human neuropathies. Nat Genet 11:281-286.

Morris JH, Hudson AR, Weddell G (1972) A study of degeneration and regeneration in the divided rat sciatic nerve based on electron microscopy. II. The development of the "regenerating unit." Z Zellforsch Mikrosk Anat 124:103-130.

Murakami T, Carcia CA, Reiter LT, Lupski JR (1996) Charcot-MarieTooth disease and related inherited neuropathies. Medicine 75:233-250.

Nelles E, Bützler C, Jung D, Temme A, Gabriel H-D, Dahl U, Traub O, Stümpel F, Jungermann K, Zielasek J, Toyka KV, Dermietzel R, Willecke K (1996) Defective propagation of signals generated by sympathetic nerve stimulation in the liver of connexin 32-deficient mice. Proc Natl Acad Sci USA 16:5351-5360.

Omori Y, Mesnil M, Yamasaki H (1996) Connexin 32 mutations from X-linked Charcot-Marie-Tooth disease patients: functional defects and dominant negative effects. Mol Biol Cell 7:907-916.

Paul DL (1995) New functions for gap junctions. Curr Opin Cell Biol 7:665-672.

Rabadan-Diehl C, Dahl G, Wener R (1994) A connexin 32 mutation associated with Charcot-Marie-Tooth disease does not affect channel formation in oocytes. FEBS Lett 351:90-94.

Reaume AG, De Sousa PA, Kulkarni S, Langille BL, Zhu D, Davies TC, Juenja SC, Kidder GM, Rossant J (1995) Cardiac malformation in neonatal mice lacking connexin 43. Science 267:1831-1834.

Scherer SS, Deschenes SM, Xu Y-I, Grinspan JB, Fischbeck KH, Paul DL (1995) Connexin 32 is a myelin-related protein in the PNS and CNS. J Neurosci 15:8281-8294.

Scherer SS, Bone LJ, Deschenes SM, Fischbeck K, Balice-Gordon RJ (1997) The role of gap junction protein connexin 32 in the myelin sheath. In: Cell biology and pathology of myelin: evolving biological concepts and therapeutic approaches (Devon RM, Doucette R, Juurlink BH, Nazarali AJ, Scheyere DJ, Verge VMK, eds). New York: Plenum.

Sereda M, Griffiths I, Pühlhofer A, Stewart H, Rossner MJ, Zimmermann F, Magyar JP, Schneider A, Hund E, Meinck H-M, Suter U, Nave K-A (1996) A transgenic rat model of Charcot-Marie-Tooth disease. Neuron 16:1049-1060.

Snipes GJ, Suter U (1995) Molecular basis of common hereditary motor and sensory neuropathies in humans and in mouse models. Brain Pathol 5:233-247.

Spray DC, Dermietzel R (1995) X-linked dominant Charcot-MarieTooth disease and other potential gap-junction diseases of the nervous system. Trends Neurosci 18:256-262.

Suter U, Snipes GJ (1995) Biology and genetics of hereditary motor and sensory neuropathies. Annu Rev Neurosci 18:45-75.

Suter U, Welcher AA, Ozcelik T, Snipes GJ, Kosaras B, Francke U, Billings GS, Sidman RL, Shooter EM (1992a) Trembler mouse carries a point mutation in a myelin gene. Nature 356:241-244.

Suter U, Moskow JJ, Welcher AA, Snipes GJ, Kosaras B, Sidman RL, Buchberg AM, Shooter EM (1992b) A leucine-to-proline mutation in the putative first transmembrane domain of the $22 \mathrm{kDa}$ peripheral myelin protein in the trembler-J mouse. Proc Natl Acad Sci USA 89:4382-4386.

Timmerman V, De Jonge P, Spoelders P, Simocovic S, Löfgren A, Nelis E, Vance J, Martin J-J, Van Broeckhoven C (1996) Linkage and mutation analysis of Charcot-Marie-Tooth neuropathy type 2 families with chromosomes 1p35-p36 and Xq13. Neurology 46:1311-1318.

Yoshimura T, Satake M, Suter U (1996) Connexin 43 is another gap junction protein in the peripheral nervous system. J Neurochem 67:1252-1258.

Zielasek J, Martini R, Toyka KV (1996) Functional abnormalities in $\mathrm{P} 0$-deficient mice resemble human hereditary neuropathies linked to P0 gene mutations. Muscle Nerve 19:946-952. 